\title{
Pengembangan Perangkat Pembelajaran Materi Bangun Datar Berorientasi Pendekatan Contextual Teaching and Learning (CTL)
}

\author{
Eri Zefni' ${ }^{1}$, Dina Dahliana ${ }^{2}$ \\ 1Universitas Negeri Padang, Padang, Indonesia \\ 2STAI SNI, Solok, Indonesia \\ *Corresponding author: dina_dahliana@staisni.ac.id
}

\begin{abstract}
Mathematics learning in elementary schools is still having problems. The problem found is that students do not understand the concept of mathematical material such as flat shapes. This study aims to develop learning tools in elementary schools. The learning tools developed are in the form of teaching materials in elementary schools. Development is carried out based on the Plomp model (Preliminary Research, Prototyping Phase and Assessment Stage) which emphasizes the context of needs (educators and students) so that learning tools are produced using the CTL approach. Based on the results of the validity trial, it can be seen from the validation of content, language, presentation, graphics and lesson plans with very valid categories.
\end{abstract}

Keywords: approach; CTL; development; learning media

\section{ABSTRAK}

Pembelajaran matematika di sekolah dasar masih mengalami permasalahan. Sebagaimana permasalahan yang ditemukan adalah siswa belum memahami konsep materi matematika seperti sangun datar. Penelitian ini bertujuan untuk mengembangkan perangkat pembelajaran di sekolah dasar. Adapun perangkat pembelajaran yang dikembangkan berupa bahan ajar di sekolah dasar. Pengembangan dilakukan berdasarkan model Plomp (Preliminary Research, Prototyping Phase and Asessment Stage) yang menekankan pada konteks kebutuhan (pendidik dan peserta didik) sehingga dihasilkan perangkat pembelajaran dengan pendekatan CTL. Berdasarkan hasil uji coba kevalidan dapat dilhat dari validasi isi, bahasa, penyajian, kegrafikaan dan RPP dengan kategori sangat valid.

Kata Kunci: CTL; pendekatan; pengembangan; perangkat pembelajaran

\section{Pendahuluan}

Proses pembelajaran matematika terdapat satu kesatuan yang tidak dapat dipisahkan antara guru yang mengajar dan siswa yang belajar. Hal ini juga didukung menurut Safrida, As'ari, \& Sisworo, (2016) mengemukakan pembelajaran matematika harus dibelajarkan dalam bentuk kesatuan karena pembelajaran matematika membutuhkan penalaran yang utuh. Proses belajar mengajar matematika merupakan kegiatan yang mengandung serangkaian persiapan guru dan siswa berdasarkan hubungan timbal balik yang berlangsung dalam situasi edukatif dalam rangka mencapai suatu tujuan tertentu Tilaar (2015). Oleh karena itu, dalam setiap jenjang pendidikan mata pelajaran matematika menjadi penting dan wajib diajarkan. Pentingnya matematika ini tiada lain bertujuan agar siswa memiliki kemampuan sebagaimana yang tercantum dalam kurikulum tingkat satuan pendidikan (Depdiknas, 2006:416) sebagai berikut:

1. Memahami konsep matematika, menjelaskan keterkaitan antar konsep dan mengaplikasikan konsep atau algoritma, secara luwes, akurat, efesien, dan tepat dalam pemecahan masalah. 
2. Menggunakan penalaran pada pola dan sifat, melakukan manipulasi matematika dalam membuat generalisasi, menyusun bukti, atau menjelaskan gagasan dan pernyataan matematika.

3. Memecahkan masalah yang meliputi kemampuan memahami masalah, merancang model matematika, menyelesaikan model dan menafsirikan solusi yang diperoleh.

4. Mengkomunikasikan gagasan dengan simbol,tabel, diagram, atau media lain untuk memperjelas keadaan atau masalah.

5. Memiliki sikap menghargai kegunaan matematika dalam kehidupan, yaitu memiliki rasa ingin tahu, perhatian dan minat dalam mempelajari matematika sifat-sifat ulet dan percaya diri dalam pemecahan masalah.

Tujuan pembelajaran matematika sangat erat degan tujaun kurikulum. Tujuan pembelajaran matematika menurut Kurikulum 2013 (Kemendikbud, 2013) menekankan pada dimensi pedagogik modern dalam pembelajaran, yaitu menggunakan pendekatan scientific (ilmiah). Hal ini juga didukung menurut (Dinni, 2018) mengemukan tujuan utama matematika adalah pemecahan dalam kehidupan sehari-hari. Hal ini membutuhkan siswa dalam berpikir HOTS. Dalam pembelajaran matematika kegiatan yang dilakukan agar pembelajaran bermakna yaitu mengamati, menanya, mencoba, menalar, menyaji, dan mencipta. Pelaksanan Pembelajaran matematika harus selaau diberikan peningkatan kualitas, karena masaih terdapat kekurangan -kekurangan yang ditemukan dilapangan. Hal ini didukung menurut Nurdeni (2010) bahwa kesalahan umum yang biasa terjadi di dalam pengajaran matematika adalah adanya anggapan bahwa apa yang diterangkan dan diucapkan oleh guru yang bersifat abstrak dapat dengan mudah dimengerti oleh siswa, sehingga guru sering menjelaskan konsep pembelajaran secara abstrak. Menurut Sulianto (2008) mengatakan bahwa guru masih menyampaikan materi pelajaran matematika dengan pendekatan tradisional yang menekankan pada latihan pengerjaan soal-soal atau drill and practice, prosedural, serta penggunaan rumus. Pada pembelajaran ini guru berfungsi sebagai pusat atau sumber materi guru yang aktif dalam pembelajaran, sedangkan siswa hanya menerima materi.

Permasalahan yang ditemui di sekolah tersebut menyebabkan hasil belajar sebagian besar siswa menjadi rendah atau di bawah batas kriteria ketuntasan minimal. Hal ini didukung menurut (Permanasari, 2016) mengatakan bahwa permasalahan matematika harus disesuaikan konteks kehidupan siswa sekolah dasar,jika tidak akan mengakibatkan permasalahan seperti, guru mengalami kesulitan dalam mencapai tujuan pembelajaran pada setiap pokok bahasan matematika yang diajarkan. Seperti halnya pada pengamatan yang saya lakukan di beberapa sekolah dasar pada kelas IV, banyak siswa yang mengalami kesulitan dalam memahami konsep pembelajaran. Kemudian guru menyuruh siswa untuk mengahafal suatu rumus dan hanya sedikit mengaitkan dengan kehidupan sehari-hari siswa. Hal ini membuat pelajaran matematika kurang bermakna bagi siswa karena kurang menghubungkan konsep matematika dengan kehidupan nyata siswa sehingga memungkinkan hasil belajar siswa menjadi rendah.

Seperti halnya pada pengamatan yang saya lakukan di beberapa sekolah dasar pada kelas IV, banyak siswa yang mengalami kesulitan dalam memahami konsep pembelajaran matematika. Salah satunya yaitu pada materi bangun datar, yaitu siswa mengalami kesulitan menentukan rumus keliling dan luas bangun datar. Kemudian guru menyuruh siswa untuk menghafal rumus keliling dan luas bangun datar dan kurang mengaitkan dengan kehidupan 
sehari-hari siswa. Hal ini membuat pelajaran matematika kurang bermakna bagi siswa karena kurang mengaitkan konsep dengan kehidupan nyata siswa sehingga memungkinkan hasil belajar siswa menjadi rendah. Rendahnya hasil belajar siswa dapat dilihat pada Penilaian Harian (PH) Matematika Semester 2 Tahun Pelajaran 2018/2019, seperti yang terlihat pada Tabel 1 berikut ini.

Tabel 1. Ketuntasan dan Rata-rata Penilaian Harian Semester II Siswa Kelas IV SDN 05 Sawahan kota Padang 2018/2019.

\begin{tabular}{cccc}
\hline $\begin{array}{c}\text { Jumlah } \\
\text { siswa }\end{array}$ & Rata-rata & \multicolumn{2}{c}{ Ketuntasan } \\
\hline 32 & 72,34 & Nilai $\geq 80$ & Nilai $<80$ \\
& & 15 & 17 \\
& Persentase & $46,87 \%$ & $53,13 \%$ \\
\hline \multicolumn{2}{c}{ Sumber: Guru Kelas IV SDN 05 Sawahan }
\end{tabular}

Berdasarkan Tabel 1 dapat dilihat bahwa masih banyak siswa yang belum mencapai Kriteria Ketuntasan Minimum (KKM). Dari 32 siswa, 15 orang (46,87\%) yang mencapai KKM sedangkan KKM yang diterapkan di sekolah adalah 80. Jika dilihat dari nilai ketuntasan terdapat selisih yang tidak terlalu besar diantara keduanya, sehingga diperlukan solusi untuk meningkatkan hasil belajar siswa. Salah satunya yaitu pendekatan Contextual Teaching and Learning (CTL). Penggunaan pendekatan pembelajaran ini diharapkan mampu meningkatkan hasil pembelajaran, memberi kesempatan yang seluas-luasnya kepada siswa untuk mengembangkan kemampuan dan menemukan sendiri konsep materi pelajaran yang dikaitkan dengan kehidupan nyata. Sedangkan menurut Fuadi (Rahmania, 2014) pembelajaran kontekstual merupakan sebuah pendekatan pembelajaran yang melibatkan paling sedikit empat prinsip utama dalam proses pembelajarannya. Pertama, proses interaksi (siswa berinteraksi secara aktif dengan guru, rekan siswa, multi-media, referensi, lingkungan dsb). Kedua, proses komunikasi (siswa mengkomunikasikan pengalaman belajar mereka dengan guru dan rekan siswa lain melalui cerita, dialog atau melalui simulasi role-play). Ketiga, proses refleksi, (siswa memikirkan kembali tentang kebermaknaan apa yang mereka telah pelajari, dan apa yang mereka telah lakukan). Keempat, proses eksplorasi (siswa mengalami langsung dengan melibatkan semua indera mereka melalui pengamatan, percobaan, penyelidikan dan/atau wawancara).

Sedangkan menurut Jamalia (2018) melalui pendekatan pembelajaran CTL yang dapat menggiring peserta didik mengaitkan antara materi yang diajarkan dengan situasi dunia nyata memberikan nilai tambah bagi pengembangan kognitif siswa dengan probabilistik menciptakan stimulus akan pengembangan psikomotorik peserta didik yang diyakini dapat meningkatkan hasil ouput dari sebuah kompetensi yang dicapai dalam pelajaran. Senada dengan pendapat tersebut, menurut Selvianiresa and S Prabawanto (2017) The Contextual Teaching and Learning (CTL) approach is an approach involving active students in the learning process to discover the concepts learned through to knowledge and experience of the students. Lebih lanjut Febriyanto, dkk (2020) mengemukakan bahwa dalam pembelajaran kontekstual dapat memperkuat pengalaman belajar siswa karena guru mengaitkan materi yang diajarkan dengan kehidupan sehari-hari siswa dan mendorong siswa untuk terlibat aktif ke dalam proses pembelajaran agar hasil pembelajaran dapat tercermin dalam kehidupan sehari-hari. 
Intinya menurut pendapat beberapa penelitian di atas, pendekatan CTL adalah pendekatan yang melibatkan siswa aktif dalam proses pembelajaran untuk menemukan konsep yang dipelajari melalui pengetahuan dan pengalaman siswa sehingga meningkatkan hasil belajar siswa.

Selanjutnya penulis melihat beberapa RPP kelas IV dari beberapa sekolah yaitu SD N 05 Sawahan, SD N 01 Sawahan dan SD N 33 Sawahan yang terdiri atas dua orang guru setiap sekolah. Berdasarkan analisis terhadap RPP, didapat hasil bahwa RPP yang digunakan guru mempunyai komponen RPP yang lengkap. Kemudian penulis melakukan wawancara dengan beberapa guru kelas IV tersebut dan diperoleh hasil bahwa mereka jarang menerapkan pendekatan CTL di kelas. Kebanyakan guru mengajar bukan berdasarkan RPP yang telah ditulis, tetapi mereka lebih terpaku pada buku teks pelajaran yang digunakan di sekolah.

Selanjutnya penulis melakukan wawancara dengan beberapa siswa kelas IV SD N 05 Sawahan Kota Padang dan siswa mengatakan bahwa pembelajaran matematika agak sulit untuk dipelajari karena menggunakan rumus dan sulit untuk dihafal. Kemudian, siswa juga mengatakan bahwa LKPD yang digunakan tulisannya terlalu kecil, tidak ada bewarna dan gambar-gambar di LKPD juga tidak bewarna, sehingga kurang menerik untuk dibaca.

Berdasarkan hasil pengamatan penulis terhadap LKPD yang digunakan siswa, ditemukan bahwa dan materi kurang menghubungkan dengan kehidupan siswa dan komponen-komponen kontekstual kurang terintegrasi di dalamnya. LKPD disajikan dengan sedikit materi, rumus-rumus yang harus dikuasai siswa, contoh soal dan diperbanyak dengan soal latihan. LKPD yang digunakan siswa tersebut dapat dilihat pada gambar 1 Berikut ini.

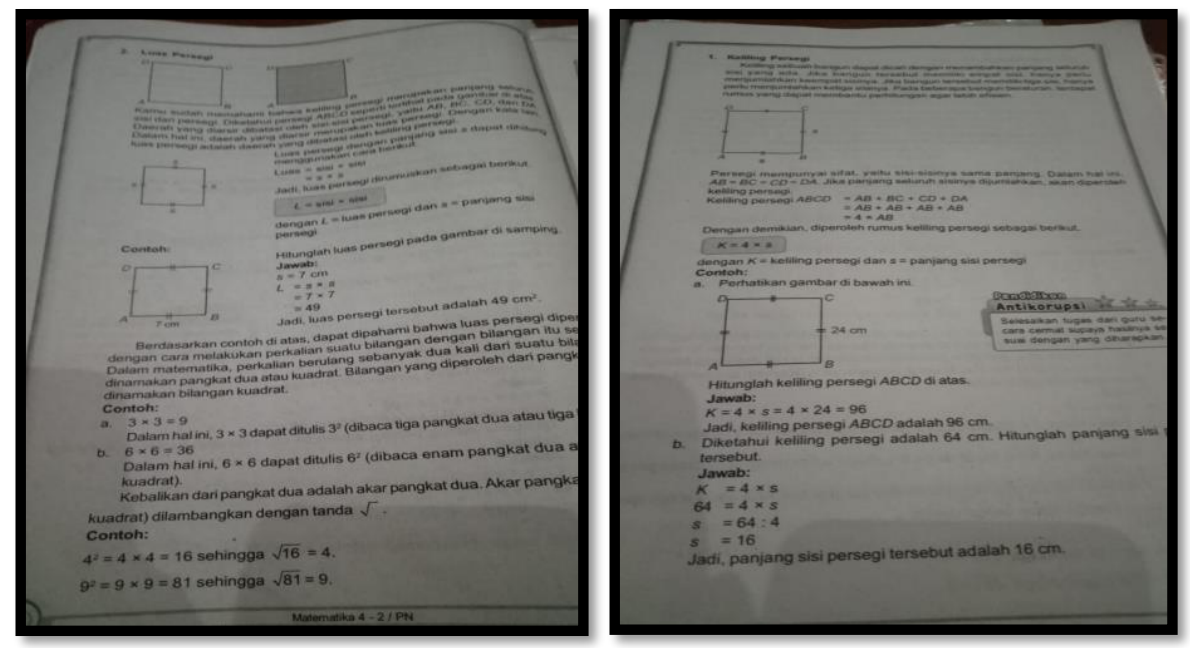

Gambar 1. Penyajian LKPD pada Penerbit A

Setelah penulis melihat penyajian LKPD yang digunakan siswa, selanjutnya dilakukan wawancara dengan beberapa guru kelas IV sekolah dasar di Kota Padang tentang penyajian LKPD dari beberapa penerbit tersebut, diperoleh informasi bahwa, isi LKPD yang dipakai kurang memaparkan materi pembelajaran. Pada LKPD tersebut langsung memaparkan rumus-rumus, contoh-contoh soal dan latihan yang akan dikerjakan siswa, tanpa adanya gambar-gambar bewarna yang menarik. Beberapa orang guru juga mengatakan bahwa penyajian LKPD kurang menarik dari segi warna, sampul LKPD mudah robek, dan warna kertas yang dipakai agak keabuan sehingga kurang menarik minat siswa untuk membacanya. 


\section{Metode Penelitian}

Penelitian ini termasuk penelitian pengembangan. Adapun prosedur penelitian yang dilakukan adalah menurut model Plomp yang terdiri dari 3 tahap, yaitu fase investigasi awal (preliminary research), fase pengembangan atau pembuatan prototype (development or prototyping phase), dan fase penilaian (assessment phase). Namun, pada penelitian ini hanya melakukan sampai pada tahap kedua. Pada pengembangan perangkat pembelajaran matematika menggunakan pendekatan CTL untuk materi bangun datar. Berikut penjelasan, prosedur penelitian yang dilakukan pada fase investigasi awal terdapat beberapa tahap sebagai berikut.

\section{Fase Investigasi Awal (Preliminary Research Phase)}

Pada tahap ini difokuskan pada analisis awal/identifikasi masalah serta kebutuhan yang diperlukan dalam melakukan pembelajaran matematika terkait dengan Rencana Pelaksanaan Pembelajaran (RPP) dan Lembar Kerja Peserta Didik (LKPD). Kegiatan ini bertujuan untuk mengumpulkan data dan menganalisis informasi, mendefenisikan masalah, mengkaji perangkat yang digunakan, dan merencanakan suatu kegiatan lanjutan.

\section{Fase Pengembangan atau Pembuatan Prototipe (Development or Prototype Phase)}

Pada fase ini disusun rancangan pengembangan perangkat pembelajaran menggunakan pendekatan CTL berupa RPP dan LKPD

\section{Hasil dan Pembahasan}

Produk yang dihasilkan dari penelitian ini adalah berupa LKPD matematika untuk siswa sekolah dasar.

\section{Preliminary Stage (Analisis Pendahuluan)}

Tahap ini dilakukan analisis terhadap kebutuhan perangkat pembelajaran yang digunakan di sekolah dasar, analisis kurikulum (K13), analisis karakteristik peserta didik, dan analisis konsep. Hasil dari analisis tersebut dapat diuraikan sebagai berikut :

\section{Analisis Kebutuhan}

Kondisi di lapangan berdasarkan hasil studi pendahuluan, perangkat pembelajaran yang digunakan belum menjadikan peserta didik tertarik untuk belajar, sedangkan dari segi desain, perangkat pembelajaran yang digunakan sudah bagus, namun perlu variasi yang sesuai dengan karakteristik peserta didik. Secara umum, perangkat pembelajaran yang dianalisis belum dapat mengadopsi pemahaman peserta didik secara utuh.

\section{Analisis Kurikulum}

Analisis kurikulum yang didapatkan oleh penulis dapat dipaparkan sebagai berikut :

Tabel 2. Analisis terhadap Kurikulum

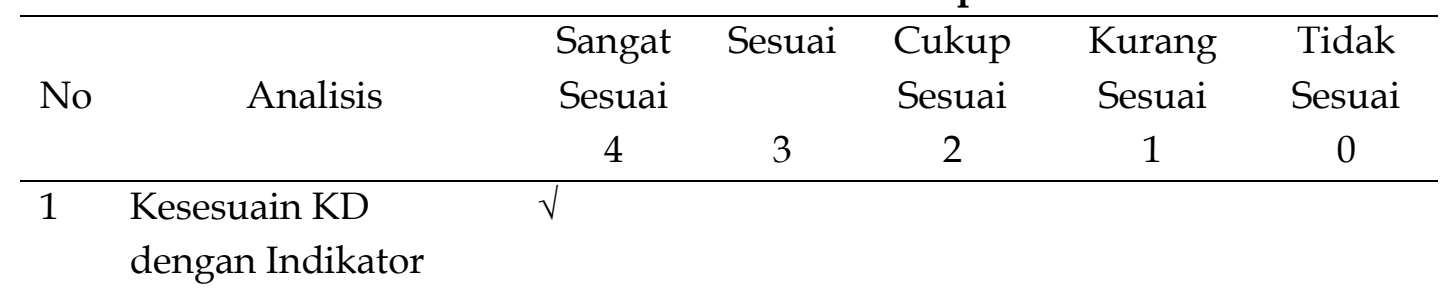


2 Kesesuain Indikator $\quad \sqrt{ }$

dengan Materi

3 Kesesuain Materi $V$

dengan OK5R

4 Kesesuaian buku

guru dengan buku

siswa

Jumlah

8

14

Total

$87,5 \%$

Persentase

Sangat Valid

Berdasarkan analisis pada tabel 2 tergambar bahwa bahan ajar yang digunakan telah berada pada kategori sangat valid dengan persentase $87,5 \%$. Artinya bahan ajar tersebut telah sesuai dengan kurikulum yang ada.

\section{Analisis Karakteristik Peserta didik}

Hasil analisis karakteristik peserta didik senang bermain, suka hal-hal baru yang menarik, memiliki rasa ingin tahu yang tinggi, suka benda-benda bergambar dan berwarnawarni. Salah satu perilaku peserta didik tersebut menyukai benda-benda yang berwarna adalah saat membuat hiasan dinding dan membaca buku, peserta didik lebih memilih buku yang bergambar.

\section{Analisis Konsep}

Analisis konsep ini bertujuan untuk mengidentifikasi konsep-konsep utama dalam membaca dalam hati dalam pembelajaran tematik terpadu di kelas V SD dan menyusun konsep-konsep secara sistematis sesuai dengan $\mathrm{KI}, \mathrm{KD}$, indikator, dan tujuan pembelajaran yang telah dianalisis.

\section{Prototyping Stage (Tahap Perancangan)}

Kegiatan selanjutnya yang dilakukan setelah tahap pendahuluan adalah merancang dan mengembangkan prototype (perangkat pembelajaran menggunakan pendekatan CTL). Prototype yang dirancang adalah materi bangun datar berdasarkan pengalaman dan pengetahuan peserta didik. 


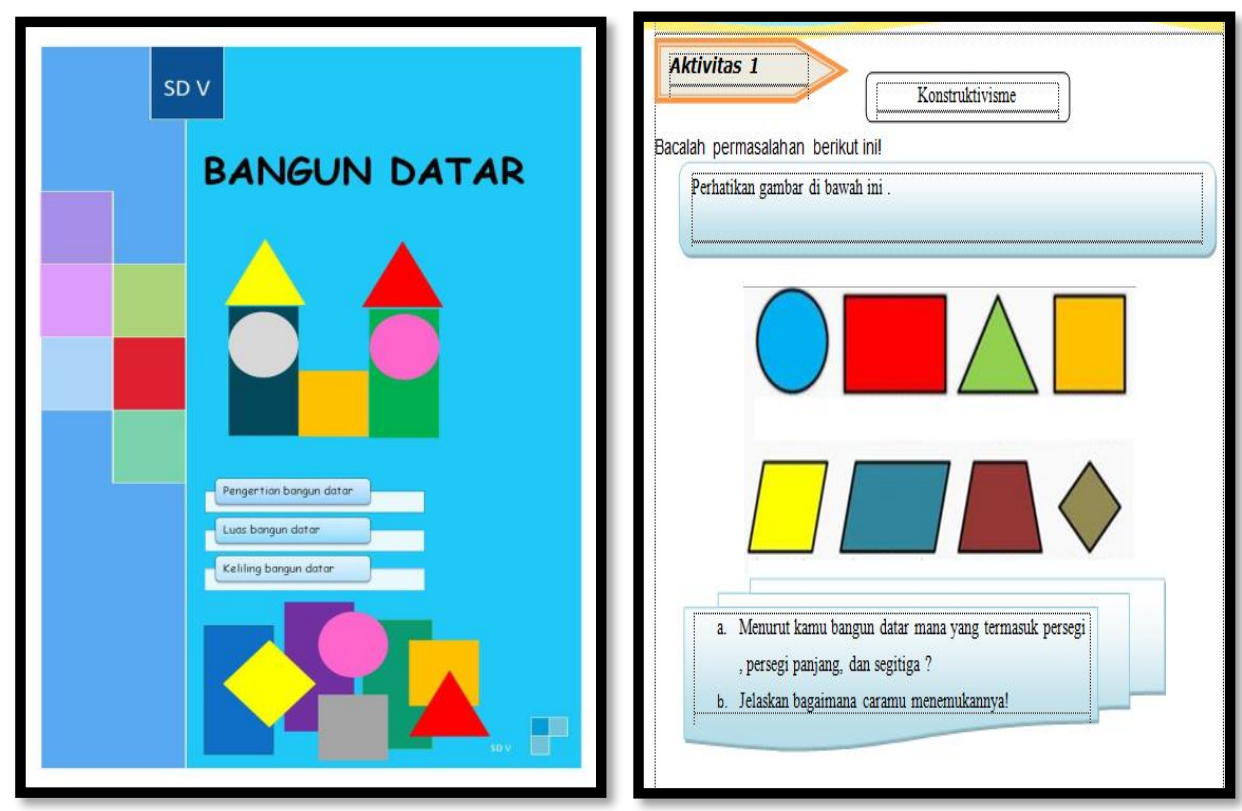

Gambar 2. LKPD

\section{Kesimpulan}

Berdasarkan paparan di atas maka dapat disimpulkan bahwa pengembangan perangkat pembelajaran matematika ini dapat digunakan untuk siswa sekolah dasar dan bisa meningkatkan hasil belajar siswa karena LKPD yang dikembangkan berisi gambar-gambar dan pemberian soal yang sangat baik.

\section{Daftar Pustaka}

Arikunto, S. (2010). Prosedur Penelitian Suatu Pendekatan Praktis. Jakarta : Rineka Cipta.

Aqib, Z. (2014). Model-Model, Media, dan Strategi Pembelajaran Kontekstual (Invatif). Bandung: Yrama Widya

Depdiknas. (2002). Kamus Besar Bahasa Indonesia. Jakarta: Balai Pustaka

Depdiknas. (2006). Permendiknas No. 22 Tahun 2006 tentang Standar Isi SD dan MI. Jakarta: Depdiknas.

Dinni, H. N. (2018). HOTS ( High Order Thinking Skills ) dan Kaitannya dengan Kemampuan Literasi Matematika. Prisma.

Febriyanto, B, dkk. (2020). Model Pembelajaran Kontekstual Berbantuan Media Puzzle Untuk Meningkatkan Hasil Belajar Siswa. Jurnal Elementaria Edukasia. Vol 3 No.2. 278286

Fitria, Y. (2019). Landasan Pembelajaran Sains Terintegrasi (Terpadu) untuk Level Dasar. Padang: Sukabina Press

Hamalik, O. (2004). Proses Belajar Mengajar. Jakarta: Bumi Aksara.

Harningsih, S, dkk. (2013). Pen ggunaan Model Pembelajaran Contextual Teaching And Learningdalam Peningkatan Pembelajaran Perkalian Bilangan Cacah Kelas II SD. FKIP, PGSD Universitas Sebelas Maret 
Heruman. (2013). Model Pembelajaran Matematika di Sekolah Dasar. Bandung: Remaja Rosdakarya

Jackson VA. Tambelk. (2013). Development of Mathematical Learning Based Contekstual Model In Southh Minahasa, Regency. Journal of Education and Practice : (online) Vol.4, No.15, 2013. Department of Mathematics Faculty of Mathematics and Natural Sciences Manado State University. http://www.iiste.org/Journals/index.php/JEP/article/viewFile/6816/6929, diakses 20 September 2017

Jamalia. (2018). Model Ctl Untuk Meningkatkan Hasil Belajar Matematika Kelas V SDN 104/IX Kedemanga. Refleksi Edukatika : Jurnal Ilmiah Kependidikan Volume 9 Nomor 1 Desember 2018 ISSN: 2087-9385 (print) dan 2528-696X (online)

Joharn. (2018). The development of learning materials using contextual teaching learning (CTL) approach oriented on the character education. Banda Aceh. Syiah Kuala University.

Lidinillah, D A M. (2009). Pembelajaran Berbasis Masalah (Problem Based Learning). Makalah, UPI Kampus Tasikmalaya.

Majid, A. (2013). Strategi Pembelajaran. Bandung: Remaja Rosdakarya

Nugroho dan Tofani. TT. Rumus-rumus Matematika Sekolah Dasar 3-4-5-6. Surabaya: Kartika

Nurdeni. (2009). Peningkatan Hasil Belajar Matematika Dalam Menyelesaikan Soal Bilangan Perkalian Dan Pembagian Di Kelas II SD. Jurnal Formatif SSN: 2088-351X. Universitas Indraprasta PGRI

Permanasari, A. (2016). STEM Education: Inovasi dalam Pembelajaran Sains. Prosiding Seminar Nasional Pendidikan Sains.

Plomp, T and Neiveen, N. (2013). An Introduction to education to educatinal design Research Procecings of the seminar conducted at the east China Normal University, Shanghai (PR China). November 23-27, 2007. 1-26.

Prasetyo, Z, dkk. (2011). Pengembangan Perangkat Pembelajaran Sains Terpadu untuk Meningkatkan Kognitif, Keterampilan Proses, Kreativitas serta Menerapkan onsep Ilmiah Peserta Didik SMP. Program Pasca Sarjana UNY

Prastowo, A. (2013). Panduan Membuat Bahan Ajar Inovatif Menciptakan Metode pembelajaran Yang menarik dan menyenangkan. Jakarta: Dira Press.

Rahmania.TT.Meningkatkan Hasil Belajar Siswa Kelas IV SDN No 2 Ogoamas II Pada Sifat-sifat Balok dan Kubus Menggunakan Pendekatan Kontekstual.Jurnal Kreatif Tadulako Online Vol. 5 No. 5 ISSN 2354-614X

Rusman. (2014). Model-model Pembelajaran. Jakarta: Raja Grafindo Persada.

Sanjaya, W. (2008). Strategi Pembelajaran Berorientasi Standar Proses Pendidikan. Jakarta: Kencana.

Safrida, L. N., As'ari, A. R., \& Sisworo, S. (2016). XI SMA. Jurnal Pendidikan Teori, Penelitian, dan Pengembangan. https://doi.org/10.17977/jp.v1i4.6201

Selvianiresa, D., \& Prabawanto, S. (2017). Contextual Teaching and Learning Approach of Mathematics in Primary Schools. Journal of Physics: Conference Series.

https:// doi.org/10.1088/1742-6596/895/1/012171

Slameto. (2013). Proses Belajar Mengajar. Jakarta: Remaja Rosdakarya.

Sudjana, N. (2010). Penilaian Hasil Proses Belajar Mengajar. Bandung: PT Remaja Rosdakarya 
Sugiyono. (2012). Metode Penelitian Pendidikan Pendekatan Kuantitatif, Kaulitatif dan $R \mathcal{E} D$. Bandung: Alfabeta.

Sulianto, J. (2008). Pendekatan Kontekstual dalam Pembelajaran Matematika untuk Meningkatkan Berpikir Kritis Pada Siswa Sekolah Dasar. Pend. Matematika FPMIPA IKIP PGRI Semarang.Vol. 4, No. 2

Suryabrata, S. (2012). Metodologi Penelitian.Jakarta: PT. Raja Grafindo Persada.

Sutikno, S. (2013). Belajar dan Pembelajaran. Lombok: Holistica

Tilaar, A. (2015). Effektivitas Pembelajaran Kontekstual dalam Mengajarkan Matematika. Jurnal Formatif 1(3): 186-191 ISSN: 2088-351X

Trianto. (2010). Mendesain Model Pembelajaran Inovatif-Progresif : Jakarta. Kencana

Zarkashi, M. (2015). Penelitian Pendidikan Matematika. Bandung: Refika Aditama 